\title{
Application of $T_{33}$-Stress to Predict the Lower Bound Fracture Toughness for Increasing the Test Specimen Thickness in the Transition Temperature Region
}

\author{
Kai Lu' ${ }^{1}$ and Toshiyuki Meshii ${ }^{2}$ \\ ${ }^{1}$ Graduate School of Engineering, University of Fukui, 3-9-1 Bunkyo, Fukui-shi, Fukui 910-8507, Japan \\ ${ }^{2}$ Faculty of Engineering, University of Fukui, 3-9-1 Bunkyo, Fukui-shi, Fukui 910-8507, Japan \\ Correspondence should be addressed to Toshiyuki Meshii; meshii@u-fukui.ac.jp
}

Received 28 December 2013; Accepted 23 January 2014; Published 13 March 2014

Academic Editor: Filippo Berto

Copyright ( $\odot 2014$ K. Lu and T. Meshii. This is an open access article distributed under the Creative Commons Attribution License, which permits unrestricted use, distribution, and reproduction in any medium, provided the original work is properly cited.

\begin{abstract}
This work was motivated by the fact that although fracture toughness of a material in the ductile-to-brittle transition temperature region $J_{c}$ exhibits the test specimen thickness (TST) effect on $J_{c}$, frequently described as $J_{c} \propto(\mathrm{TST})^{-1 / 2}$, experiences a contradiction that is deduced from this empirical formulation; that is, $J_{c}=0$ for large TST. On the other hand, our previous works have showed that the TST effect on $J_{c}$ could be explained as a difference in the out-of-plane constraint and correlated with the out-of-plane $T_{33}$-stress. Thus, in this work, the TST effect on $J_{c}$ for the decommissioned Shoreham reactor vessel steel A533B was demonstrated from the standpoint of out-of-plane constraint. The results validated that $T_{33}$ was effective for describing the $J_{c}$ decreasing tendency. Because the Shoreham data included a lower bound $J_{c}$ for increasing TST, a new finding was made that $T_{33}$ successfully predicted the lower bound of $J_{c}$ with increasing TST. This lower bound $J_{c}$ prediction with $T_{33}$ conquered the contradiction that the empirical $J_{c} \propto(\mathrm{TST})^{-1 / 2}$ predicts $J_{c}=0$ for large TST.
\end{abstract}

\section{Introduction}

The cleavage fracture toughness $J_{c}$ of a material in the ductile-to-brittle transition (DBT) temperature region, which is important in the assessment of aging steel structures and reactor pressure vessels, has been known to exhibit test specimen size effects, even when tested using a standardized specimen [1-9]. For example, $J_{c}$ obtained using a shallow cracked specimen exhibits a higher value than that obtained using a deep cracked specimen. Another known size effect is the test specimen thickness (TST) effect on $J_{c}$, hereafter abbreviated as the TST effect on $J_{c}$, which is described as $J_{c} \propto B^{(-1 / 2)}(B \equiv$ TST) $[2,10]$. The two most physically logical explanations in general are the statistical weakest link (SWL) size effect and the loss of the crack-tip constraint [2]. Both explanations lead to an increasing toughness with decreasing TST. The difference in $J_{c}$ obtained with a different planar specimen configuration, including the crack depth [4], has been explained as the differences in the crack-tip constraint or the hydrostatic stress triaxiality, which $J$ fails to describe $[3,5-9]$.
However, the TST effect has been explained in terms of the SWL size effect being dominant $[6,11-13]$, even though $J_{c}$ does not decrease indefinitely with thickness [6], which contradicts the prediction from the SWL size effect [2].

Based on the above, the authors believed that the contribution of the crack-tip constraint to the TST effect on $J_{c}$ could be demonstrated if the TST effect (especially the bounded nature of $J_{c}$ with increasing TST) was demonstrated using a series of nonstandard test specimens whose planar configurations are identical but whose thickness-to-width ratios, $B / W$, are changed to realize different thickness specimens and if the test results were reproduced using finite element analysis (FEA). This use of nonstandard test specimens was prompted by the inability to predict the bounded nature of $J_{c}$ using the SWL formulation. This prediction was thought to be enabled by these specimens because the out-of-plane cracktip constraint will increase and saturate with increasing $B / W$, but the in-plane crack-tip constraint will not change. The fracture toughness tests for a series of nonstandard compacttension (CT) and three-point-bend $(3 \mathrm{~PB}$, also named as 


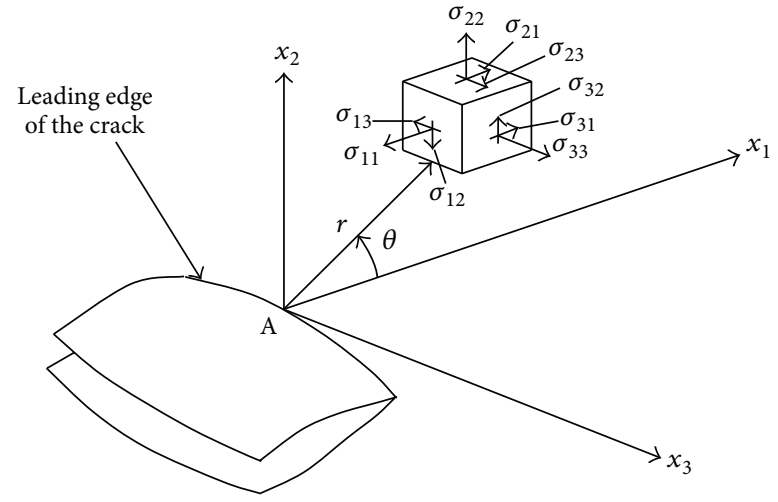

FIGURE 1: Three-dimensional coordinate system for the region along the crack front.

SE(B) specimen) specimens for $0.55 \%$ carbon steel S55C [14-16] and $0.40 \%$ carbon chromium molybdenum steel SCM440 [17] validated the noticeable contribution of the outof-plane crack-tip constraint to the TST effects on $J_{c}$, and the constraint parameter $T_{33}$-stress was demonstrated to be effective for correlating this out-of-plane crack-tip constraint with the TST effects on $J_{c}$ [14-17]. These results indicated a possibility of correlating the fracture toughness of a test specimen and the crack-like flaws in the structure more accurately by considering $T_{33}$.

This work is an extension of our previous studies regarding the point that the contribution of the out-of-plane cracktip constraint to the TST effect on $J_{c}$ was demonstrated for the decommissioned Shoreham reactor vessel steel, ASTM A533 Grade B Class 1 (A533B) [1], which is experimentally formulated as $J_{c}[\mathrm{~N} / \mathrm{mm}]=2.3 \cdot\left|T_{33}\right|^{0.6}\left(80 \leq\left|T_{33}\right| \leq 320 \mathrm{MPa}\right)$ to describe the $J_{c}$ decreasing tendency for increasing TST. Because the Shoreham data included a lower bound of $J_{c}$ for increasing TST, a new finding was made that $T_{33}$ successfully predicted the lower bound $J_{c}$ with increasing TST. This lower bound $J_{c}$ prediction with $T_{33}$ resolves the contradiction that the empirical $J_{c} \propto(\mathrm{TST})^{-1 / 2}$ predicts $J_{c}=0$ for large TST.

\section{TST Effect on $J_{c}$ Described by the $T_{33}$-Stress}

2.1. T-Stress. In an isotropic linear elastic body containing a crack subjected to symmetric (mode I) loading, the leading two terms in a series expansion of the stress field very near to the crack front are [18]

$$
\left\{\begin{array}{l}
\sigma_{11} \\
\sigma_{22} \\
\sigma_{33} \\
\sigma_{12} \\
\sigma_{23} \\
\sigma_{31}
\end{array}\right\}=\frac{K_{\mathrm{I}}}{\sqrt{2 \pi r}}\left\{\begin{array}{c}
\cos \frac{\theta}{2}\left(1-\sin \frac{\theta}{2} \sin \frac{3 \theta}{2}\right) \\
\cos \frac{\theta}{2}\left(1+\sin \frac{\theta}{2} \sin \frac{3 \theta}{2}\right) \\
2 \nu \cos \frac{\theta}{2} \\
\sin \frac{\theta}{2} \cos \frac{\theta}{2} \cos \frac{3 \theta}{2} \\
0 \\
0 \\
T_{33}=E \varepsilon_{33}+v T_{11},
\end{array}\right\}+\left\{\begin{array}{c}
T_{11} \\
0 \\
T_{33} \\
0 \\
0 \\
0
\end{array}\right\},
$$

where $r$ and $\theta$ are the in-plane polar coordinates of the plane normal to the crack front, as shown in Figure 1, and $K_{\mathrm{I}}$ is the local mode I stress intensity factor (SIF) at location A. Here $x_{1}$ is the direction formed by the intersection of the plane normal to the crack front and the crack plane. The terms $T_{11}$ and $T_{33}$ are the amplitudes of the second-order terms in the three-dimensional series expansion of the crack front stress field in the $x_{1}$ and $x_{3}$ directions, respectively.

2.2. TST Effect on $J_{c}$ Described by $T_{33}$-Stress. In our previous works $[14,15,17]$, the following relationships were obtained for $0.55 \%$ carbon steel S55C $[14,15]$ and $0.40 \%$ carbon chromium molybdenum steel SCM440 [17] with both CT and 3PB specimens:

$$
\begin{gathered}
\text { S55C at } 20^{\circ} \mathrm{C}:\left\{\begin{array}{c}
J_{\mathrm{c}}[\mathrm{N} / \mathrm{mm}]=2.6\left[\mathrm{~N}^{1 / 2}\right] \cdot\left|T_{33}\right|^{1 / 2} \\
\left(\mathrm{CT}, 60 \leq\left|T_{33}\right| \leq 180 \mathrm{MPa}\right) \\
J_{\mathrm{c}}[\mathrm{N} / \mathrm{mm}]=3.1\left[\mathrm{~N}^{1 / 2}\right] \cdot\left|T_{33}\right|^{1 / 2} \\
\left(3 \mathrm{~PB}, 80 \leq\left|T_{33}\right| \leq 160 \mathrm{MPa}\right),
\end{array}\right. \\
\mathrm{SCM} 440 \text { at }-50^{\circ} \mathrm{C}:\left\{\begin{array}{c}
J_{\mathrm{c}}[\mathrm{N} / \mathrm{mm}]=4.6\left[\mathrm{~N}^{1 / 2}\right] \cdot\left|T_{33}\right|^{1 / 2} \\
\left(\mathrm{CT}, 120 \leq\left|T_{33}\right| \leq 260 \mathrm{MPa}\right) \\
J_{\mathrm{c}}[\mathrm{N} / \mathrm{mm}]=4.8\left[\mathrm{~N}^{1 / 2}\right] \cdot\left|T_{33}\right|^{1 / 2} \\
\left(3 \mathrm{~PB}, 100 \leq\left|T_{33}\right| \leq 210 \mathrm{MPa}\right) .
\end{array}\right.
\end{gathered}
$$

The object of these works was to demonstrate that the outof-plane crack-tip constraint has a noticeable contribution to the TST effect on $J_{c}$ and that the TST effect can be correlated with a mechanical parameter $T_{33}$ (expressing the out-of-plane crack-tip constraint).

Because the bounded nature of $J_{c}$ with increasing TST could not be realized with the tested specimens of thicknessto-width ratios $B / W=0.25,0.4$, and 0.5 , the tested results with large $B / W$ were searched in the published documents, and the decommissioned Shoreham reactor vessel steel data [1] were found to fulfill our requirement. In the following, Shoreham's $J_{c}$ data were compiled to validate the relationship $J_{c} \propto\left|T_{33}\right|^{\gamma}$ ( $\gamma$ : material constant) and, in particular, to correlate the bounded nature of $J_{c}$ for increasing TST with $T_{33}$.

\section{Compilation of the Decommissioned Shoreham Reactor Vessel Steel Fracture Toughness Test Data from the Standpoint of Out-of-Plane Constraint}

3.1. Prediction of a Lower Bound of $J_{c}$ for Increasing TST with $T_{33}$. From our recent elastic FEA results for the nonstandard $3 \mathrm{~PB}$ specimen with various $B / W$ values, as shown in Figure 2(a), the midplane $T_{33}$ normalized in the form of $\beta_{33}=$ $T_{33}(\pi a)^{1 / 2} / K_{\mathrm{I}}$ exhibited a strong dependence on $B / W$ [17]. $\beta_{33}$ was negative for $B / W<1.5$, whereas it was positive and approached $v \beta_{11}\left(\beta_{11}=T_{11}(\pi a)^{1 / 2} / K_{\mathrm{I}}\right)$ for increasing TST. 


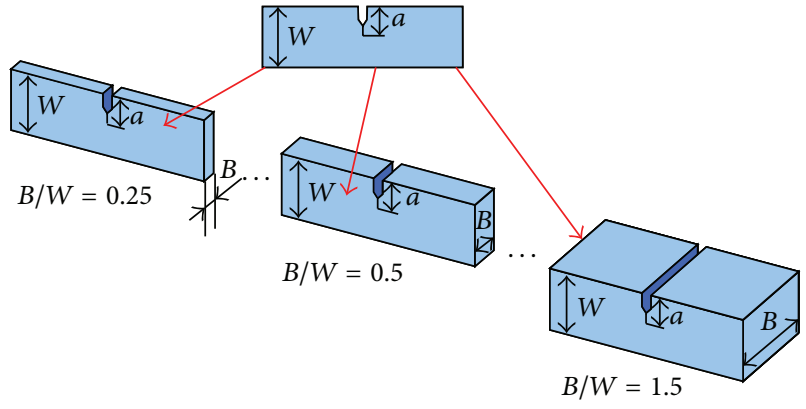

$W=$ constant

$B$ : variable

(a)

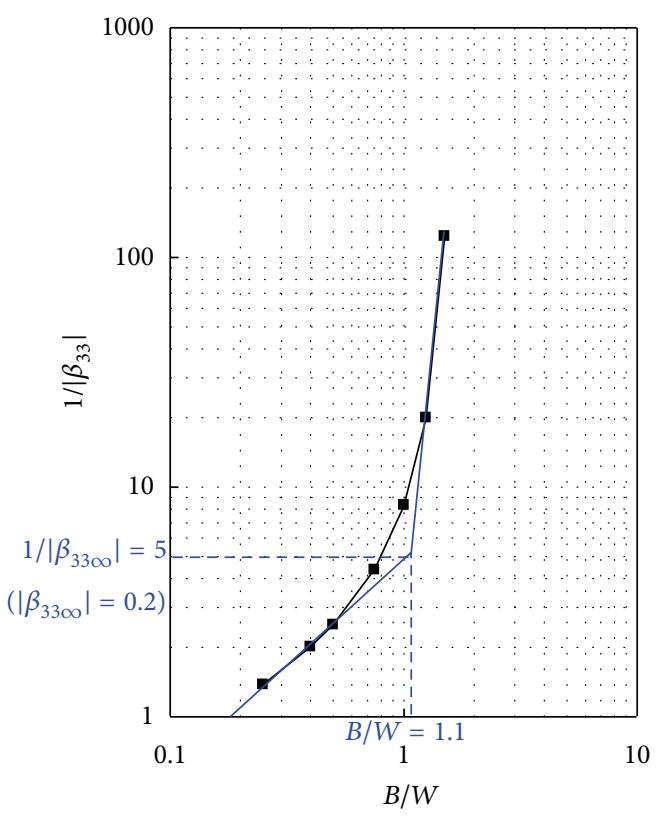

(b)

FIgURE 2: The TST effect on the normalized $T_{33}$ of the nonstandard $3 \mathrm{~PB}$ specimen at the specimen midplane $(W=25 \mathrm{~mm}, a / W=0.5$; $\nu=0.3)[16]$ recompiled in the log-log form.

The negative $\beta_{33}$ recompiled in the $\log$-log form, as shown in Figure 2(b), exhibited $\left|\beta_{33}\right| \propto(B / W)^{-1}$ for $B / W \leq 0.5$ and a bounded nature for $B / W \geq 1.1$ in an engineering sense. This engineering onset of the bounded nature of $\left|\beta_{33}\right|=$ 0.2 was defined as the bounded value $\left|\beta_{3300}\right|$. Because the SIF corresponding to the fracture load $K_{c}$ exhibited a small change with TST [14-17], it was thought that the experimental formulation $J_{c}=C\left|T_{33}\right|^{\gamma}$ (C, $\gamma$ : material constants) together with $\left|T_{3300}\right|=\left|\beta_{3300}\right| \cdot K_{c} /(\pi a)^{1 / 2}$ could predict the lower bound value of $J_{c \min }$ with increasing TST as follows:

$$
J_{c \min }=C\left|T_{33 \infty}\right|^{\gamma}=C\left\{\frac{\left|\beta_{33 \infty}\right| K_{\mathrm{c}}}{(\pi a)^{1 / 2}}\right\}^{\gamma} .
$$

\subsection{Compilation of the Decommissioned Shoreham Reactor} Vessel Steel Fracture Toughness Test Data from the Standpoint of the Out-of-Plane Constraint. To determine whether the relationship $J_{c}=C\left|T_{33}\right|^{\gamma}$ is valid for other materials and especially whether the lower bound $J_{c \min }$ can be predicted by $T_{33}$, the decommissioned Shoreham reactor vessel steel [1] A533B was selected in this work because a large amount of fracture toughness test data for A533B with various thickness $3 \mathrm{~PB}$ specimens at a common temperature $-91^{\circ} \mathrm{C}$ (located in the DBT temperature region) was published. A more detailed description for the fracture toughness tests can be found in [1].

Here, the fracture toughness test data for $3 \mathrm{~PB}$ specimens with width $W=25.4$ and $50.8 \mathrm{~mm}$ whose thicknesses $B$ $=8,15.9,31.8$, and $63.5 \mathrm{~mm}$ (thickness-to-width ratio $B / W$ $=0.157 \sim 2.5$ ) were recompiled from the published results [1] on the standpoint of the out-of-plane crack-tip constraint. Although the eight replicate fracture toughness test results reported in [1] for these $3 \mathrm{~PB}$ specimens were considered to be valid overall, some of the individual $K_{I c}$ datum still appeared to deviate greatly from the remainder in each $B / W$ set. Considering the fact that the $K_{I c}$ scatter from eight replicate tests always exceeded the guideline value as given in ASTM E1921 [19], we thought it was necessary to recompile these test results because the impact of the apparent deviated $K_{J c}$ datum for each $B / W$ set was considered non-negligible in studying the TST effect on the cleavage fracture toughness. Therefore, the cases with maximum and minimum $K_{J c}$ values were excluded, with the test results of the remaining cases summarized in Tables 1 and 2.

The $K_{c}$ in the tables was obtained as the SIF $K$ corresponding to the fracture load $P_{c}$ from the following equation in ASTM E1921 [19]:

$$
K=\frac{P S}{B W^{3 / 2}} f\left(\frac{a}{W}\right) .
$$

Here, $S=4 W$ is the support span, and $f$ is a function of $a / W$, which is given in the ASTM E1921 [19].

$K_{J c}$ in the table is the fracture toughness in terms of the SIF. $J_{c}$ was calculated from $K_{J c}$ as $J_{c}=K_{J c}^{2} \cdot\left(1-v^{2}\right) / E$, where the value of Young's modulus of $E=207.9 \mathrm{GPa}$ and the value of Poisson's ratio of $v=0.29$ were used, as specified in [20]. $T_{33 c}$, which reflects the fracture load and the actual crack length, was calculated from the $\beta_{33}$ solutions of elastic FEA, as summarized in the Appendix. $\mu$ and $\Sigma$ are the average and standard deviation of each value, respectively. $2 \Sigma / \mu$ is a reference value that was used to represent the magnitude of the data scatter.

It is seen from Tables 1 and 2 that, except for the case of $W=50.8 \mathrm{~mm}$ with a very thin thickness $B=8 \mathrm{~mm}$ $(2 \Sigma / \mu=63.8 \%)$, the reference value $2 \Sigma / \mu$ of $K_{J c}$ was in the range from $33.1 \%$ to $45.6 \%$ for the selected specimens, which 
TABLE 1: Fracture toughness test and FEA results for A533B compiled from the Shoreham reactor pressure vessel data [1] (3PB, $W=25.4 \mathrm{~mm}$, $-91^{\circ} \mathrm{C} ; \mu$ : average, $\Sigma$ : standard deviation).

\begin{tabular}{|c|c|c|c|c|c|c|c|c|c|c|}
\hline$B \mathrm{~mm}(B / W)$ & Serial number & 1 & 2 & 3 & 4 & 5 & 6 & $\mu$ & $\Sigma$ & $2 \Sigma / \mu \%$ \\
\hline \multirow{6}{*}{$8(0.315)$} & $a / W^{*}$ & 0.5 & 0.49 & 0.5 & 0.5 & 0.5 & 0.5 & 0.50 & 0.0 & 1.6 \\
\hline & $P_{c} \mathrm{kN}^{*}$ & 9.61 & 9.49 & 9.02 & 9.52 & 9.61 & 8.99 & 9.37 & 0.3 & 6.2 \\
\hline & $K_{c} \mathrm{MPa} \mathrm{m}^{1 / 2}$ & 80.3 & 76.8 & 75.3 & 79.6 & 80.3 & 75.1 & 77.9 & 2.4 & 6.3 \\
\hline & $K_{J c} \mathrm{MPa} \mathrm{m}^{1 / 2^{*}}$ & 149 & 131 & 118 & 124 & 157 & 98 & 129.5 & 21.4 & 33.1 \\
\hline & $J_{c} \mathrm{~N} / \mathrm{mm}$ & 97.8 & 75.6 & 61.3 & 67.7 & 108.6 & 42.3 & 75.6 & 24.3 & 64.3 \\
\hline & $T_{33 c} \mathrm{MPa}$ & -234.4 & -226.0 & -219.9 & -232.2 & -234.4 & -219.1 & -227.7 & 7.0 & -6.2 \\
\hline \multirow{6}{*}{$15.9(0.63)$} & $a / W^{*}$ & 0.52 & 0.52 & 0.52 & 0.52 & 0.52 & 0.52 & 0.52 & 0.0 & 0.0 \\
\hline & $P_{c} \mathrm{kN}^{*}$ & 18.2 & 18.8 & 17.4 & 17.3 & 18.4 & 17.9 & 18.0 & 0.6 & 6.2 \\
\hline & $K_{c} \mathrm{MPa} \mathrm{m}^{1 / 2}$ & 81.7 & 84.1 & 78.2 & 77.6 & 82.5 & 80.3 & 80.7 & 2.5 & 6.2 \\
\hline & $K_{J c} \mathrm{MPa} \mathrm{m}^{1 / 2^{*}}$ & 130 & 126 & 92 & 89 & 131 & 100 & 111.3 & 19.8 & 35.5 \\
\hline & $J_{c} \mathrm{~N} / \mathrm{mm}$ & 74.5 & 69.9 & 37.3 & 34.9 & 75.6 & 44.1 & 56.0 & 19.3 & 68.8 \\
\hline & $T_{33 c} \mathrm{MPa}$ & -112.7 & -116.0 & -107.9 & -107.1 & -113.8 & -110.9 & -111.4 & 3.5 & -6.2 \\
\hline \multirow{6}{*}{$31.8(1.25)$} & $a / W^{*}$ & 0.52 & 0.52 & 0.52 & 0.52 & 0.53 & 0.52 & 0.52 & 0.0 & 1.6 \\
\hline & $P_{c} \mathrm{kN}^{*}$ & 35.4 & 37.5 & 38.5 & 32.9 & 35.1 & 34.6 & 35.7 & 2.0 & 11.4 \\
\hline & $K_{c} \mathrm{MPa} \mathrm{m}^{1 / 2}$ & 79.3 & 84.1 & 86.4 & 73.8 & 81.2 & 77.6 & 80.4 & 4.5 & 11.3 \\
\hline & $K_{J c} \mathrm{MPa} \mathrm{m}^{1 / 2^{*}}$ & 89 & 126 & 128 & 84 & 96 & 90 & 102.2 & 19.6 & 38.4 \\
\hline & $J_{c} \mathrm{~N} / \mathrm{mm}$ & 34.9 & 69.9 & 72.2 & 31.1 & 40.6 & 35.7 & 47.4 & 18.6 & 78.4 \\
\hline & $T_{33 c} \mathrm{MPa}$ & -12.5 & -13.3 & -13.6 & -11.6 & -9.8 & -12.2 & -12.2 & 1.4 & -22.4 \\
\hline \multirow{6}{*}{$63.5(2.5)$} & $a / W^{*}$ & 0.5 & 0.49 & 0.49 & 0.5 & 0.49 & 0.49 & 0.49 & 0.0 & 2.1 \\
\hline & $P_{c} \mathrm{kN}^{*}$ & 76.3 & 57.9 & 77.0 & 49.2 & 60.4 & 70.4 & 65.2 & 11.2 & 34.2 \\
\hline & $K_{c} \mathrm{MPa} \mathrm{m}^{1 / 2}$ & 80.3 & 59.0 & 78.6 & 51.7 & 61.6 & 71.8 & 67.2 & 11.5 & 34.2 \\
\hline & $K_{J c} \mathrm{MPa} \mathrm{m}^{1 / 2^{*}}$ & 94 & 62 & 89 & 52 & 63 & 78 & 73.0 & 16.6 & 45.6 \\
\hline & $J_{c} \mathrm{~N} / \mathrm{mm}$ & 38.9 & 16.9 & 34.9 & 11.9 & 17.5 & 26.8 & 24.5 & 10.8 & 88.4 \\
\hline & $T_{33 c} \mathrm{MPa}$ & 15.0 & 9.3 & 12.4 & 9.7 & 9.7 & 11.3 & 11.3 & 2.2 & 39.0 \\
\hline
\end{tabular}

${ }^{*}$ Published results in [1].

satisfied the guideline for $2 \Sigma / \mu$ given in ASTM E1921 [19] for $K_{I c}$. Here the guideline for $2 \Sigma / \mu$ is $56(1-20 / \mu) \%$ with the range from $40.7 \%$ to $47.4 \%$ for the data in Tables 1 and 2 . As a result, it could be concluded that the scatter in the $K_{J c}$ data of the selected specimens summarized in the tables was acceptable in an engineering sense.

One interesting fact was that the change in $K_{c}$, that is, the SIF for the fracture load $P_{c}$, exhibited a relatively small dependence on $B / W$, although a significant change in the fracture toughness $J_{c}$ was observed. The average $K_{c}$ for each $B / W$ was in the range from 67.2 to $80.7 \mathrm{MPa} \mathrm{m}^{1 / 2}$ for $W=$ $25.4 \mathrm{~mm}$ and 75.8 to $95.7 \mathrm{MPa} \mathrm{m}^{1 / 2}$ for $W=50.8 \mathrm{~mm}$. This result was similar to the experience with S55C [14-16] and SCM440 [17], which validated one of the assumptions used to predict the lower bound of $J_{c}$ for large TST proposed in Section 3.1.

The relationship between $J_{c}$ and $T_{33 c}$ for A533B is shown in Figure 3; note that $T_{33 c}$ reflects the fracture load and the actual crack length for each $B / W$, as summarized in Table 1 and 2 . The solid marks represent the average for each $B / W$. The difference in $W$ was distinguished by the color of the marks. As shown in Figure 3, all the data in Tables 1 and 2 are fitted to the power law expression

$$
J_{c}[\mathrm{~N} / \mathrm{mm}]=2.3 \cdot\left|T_{33}\right|^{0.6}
$$

for A533B tested using $3 \mathrm{~PB}$ specimens at $-91^{\circ} \mathrm{C}$. $J_{c}$ seemed to be bounded for $2\left|T_{33 c}\right|<100 \mathrm{MPa}$. The bounded value of $J_{c}$ in Figure 3 for the case of $W=25.4 \mathrm{~mm}$ was obtained from Table 1 as an average $J_{c}$ for the specimens of $B / W=1.25$ and 2.5. For the case of $W=50.8 \mathrm{~mm}$, the bounded $J_{c}$ was obtained from Table 2 as an average for $B / W=1.25$.

On the other hand, if the method to predict the lower bound $J_{c \text { min }}$ for increasing TST proposed in Section 3.1 is applied, for the case of $W=25.4 \mathrm{~mm}$ as an example, first $\left|T_{33 \infty}\right|$ is calculated with $\left|\beta_{33 \infty}\right|=0.2$ for the case of $a / W=$ 0.5 and $K_{c}=79.7 \mathrm{MPa} \mathrm{m}^{1 / 2}$ (the averaged SIF for $B / W=$ $0.315 \sim 1.25$ was used from Table 1 , considering the fact that $K_{c}$ exhibited a very small dependence on TST) as $\left|T_{33 \infty 0}\right|=$ $\left|\beta_{33 \infty}\right| \cdot K_{c} /(\pi a)^{1 / 2}=0.2 \times 79.7 /(\pi 0.0127)^{1 / 2}=79.8 \mathrm{MPa}$. Then, the lower bound $J_{c \text { min }}$ is predicted from (3) as $J_{c \text { min }}=$ $2.3 \times|79.8|^{0.6}=31.8 \mathrm{~N} / \mathrm{mm}$, and it was close to experimental average $36.0 \mathrm{~N} / \mathrm{mm}$. In case of $W=50.8 \mathrm{~mm}$, by the same method, $J_{c \min }=27.2 \mathrm{~N} / \mathrm{mm}$ was obtained and was also very close to the experimental average $27.9 \mathrm{~N} / \mathrm{mm}$.

In summary, the TST effect on $J_{c}$ of A533B could be described by $T_{33}$, as $J_{c}=2.3 \cdot\left|T_{33}\right|^{0.6}$ for $80 \leq\left|T_{33}\right| \leq$ $320 \mathrm{MPa}$. In addition, the lower bound value of $J_{c \text { min }}=$ $31.8 \mathrm{~N} / \mathrm{mm}$ was obtained for $W=25.4 \mathrm{~mm}$ and $J_{c \min }=$ $27.2 \mathrm{~N} / \mathrm{mm}$ for $W=50.8 \mathrm{~mm}$; both of them were close to 
TABLE 2: Fracture toughness test and FEA results for A533B compiled from the Shoreham reactor pressure vessel data $[1](3 \mathrm{~PB}, W=50.8 \mathrm{~mm}$, $-91^{\circ} \mathrm{C}$; $\mu$ : average, $\Sigma$ : standard deviation).

\begin{tabular}{|c|c|c|c|c|c|c|c|c|c|c|}
\hline$B \mathrm{~mm}(B / W)$ & Serial number & 1 & 2 & 3 & 4 & 5 & 6 & $\mu$ & $\Sigma$ & $2 \Sigma / \mu \%$ \\
\hline \multirow{6}{*}{$8(0.157)$} & $a / W^{*}$ & 0.48 & 0.49 & 0.48 & 0.49 & 0.49 & 0.48 & 0.49 & 0.0 & 2.3 \\
\hline & $P_{c} \mathrm{kN}^{*}$ & 17.4 & 15.5 & 16.8 & 19.4 & 15.2 & 17.7 & 17.0 & 1.5 & 18.1 \\
\hline & $K_{c} \mathrm{MPa} \mathrm{m}^{1 / 2}$ & 96.6 & 88.7 & 93.2 & 110.8 & 86.8 & 98.0 & 95.7 & 8.6 & 17.9 \\
\hline & $K_{J c} \mathrm{MPa} \mathrm{m}^{1 / 2^{*}}$ & 122 & 101 & 112 & 205 & 94 & 123 & 126.2 & 40.3 & 63.8 \\
\hline & $J_{c} \mathrm{~N} / \mathrm{mm}$ & 65.6 & 44.9 & 55.3 & 185.1 & 38.9 & 66.7 & 76.1 & 54.5 & 143.4 \\
\hline & $T_{33 c} \mathrm{MPa}$ & -327.7 & -300.5 & -316.0 & -375.3 & -294.2 & -332.3 & -324.3 & 29.0 & -17.9 \\
\hline \multirow{6}{*}{$15.9(0.313)$} & $a / W^{*}$ & 0.49 & 0.49 & 0.49 & 0.49 & 0.49 & 0.49 & 0.49 & 0.0 & 0.0 \\
\hline & $P_{c} \mathrm{kN}^{*}$ & 36.7 & 30.5 & 35.9 & 34.9 & 23.3 & 35.9 & 32.9 & 5.2 & 31.6 \\
\hline & $K_{c} \mathrm{MPa} \mathrm{m}^{1 / 2}$ & 105.8 & 88.0 & 103.4 & 100.5 & 67.1 & 103.4 & 94.7 & 14.9 & 31.6 \\
\hline & $K_{J c} \mathrm{MPa} \mathrm{m}^{1 / 2^{*}}$ & 129 & 93 & 122 & 121 & 69 & 122 & 109.3 & 23.4 & 42.8 \\
\hline & $J_{c} \mathrm{~N} / \mathrm{mm}$ & 73.3 & 38.1 & 65.6 & 64.5 & 21.0 & 65.6 & 54.7 & 20.5 & 74.8 \\
\hline & $T_{33 c} \mathrm{MPa}$ & -225.4 & -187.4 & -220.3 & -214.1 & -142.9 & -220.2 & -201.7 & 31.8 & -31.6 \\
\hline \multirow{6}{*}{$31.8(0.63)$} & $a / W^{*}$ & 0.5 & 0.5 & 0.5 & 0.5 & \multirow{6}{*}{-} & \multirow{6}{*}{ - } & 0.50 & 0.0 & 0.0 \\
\hline & $P_{c} \mathrm{kN}^{*}$ & 62.7 & 56.5 & 60.6 & 43.6 & & & 55.9 & 8.5 & 30.6 \\
\hline & $K_{c} \mathrm{MPa} \mathrm{m}^{1 / 2}$ & 93.2 & 83.9 & 90.0 & 64.9 & & & 83.0 & 12.7 & 30.6 \\
\hline & $K_{J c} \mathrm{MPa} \mathrm{m}^{1 / 2^{*}}$ & 99 & 88 & 96 & 66 & & & 87.3 & 14.9 & 34.2 \\
\hline & $J_{c} \mathrm{~N} / \mathrm{mm}$ & 43.2 & 34.1 & 40.6 & 19.2 & & & 34.3 & 10.8 & 62.7 \\
\hline & $T_{33 c} \mathrm{MPa}$ & -98.4 & -88.6 & -95.1 & -68.5 & & & -87.7 & 13.4 & -30.6 \\
\hline \multirow{6}{*}{$63.5(1.25)$} & $a / W^{*}$ & 0.51 & 0.52 & 0.52 & 0.51 & 0.52 & \multirow{6}{*}{-} & 0.52 & 0.0 & 2.1 \\
\hline & $P_{c} \mathrm{kN}^{*}$ & 119.0 & 77.3 & 107.1 & 96.4 & 84.6 & & 96.9 & 16.8 & 34.7 \\
\hline & $K_{c} \mathrm{MPa} \mathrm{m}^{1 / 2}$ & 91.5 & 61.4 & 85.0 & 74.0 & 67.1 & & 75.8 & 12.4 & 32.7 \\
\hline & $K_{J c} \mathrm{MPa} \mathrm{m}^{1 / 2^{*}}$ & 99 & 62 & 86 & 76 & 70 & & 78.6 & 14.4 & 36.6 \\
\hline & $J_{c} \mathrm{~N} / \mathrm{mm}$ & 43.2 & 16.9 & 32.6 & 25.4 & 21.6 & & 27.9 & 10.3 & 73.5 \\
\hline & $T_{33 c} \mathrm{MPa}$ & -13.2 & -7.2 & -10.0 & -10.7 & -7.9 & & -9.8 & 2.4 & -48.8 \\
\hline
\end{tabular}

${ }^{*}$ Published results in [1].

the experimental average value, which indicated that $T_{33}$ can successfully predict the bounded nature of $J_{c}$.

\section{Discussion}

In this work, the TST effect and the bounded nature of $J_{c}$ observed for the decommissioned Shoreham reactor vessel steel, $\mathrm{A} 533 \mathrm{~B}$, at $-91^{\circ} \mathrm{C}$, which is in the DBT range [1], were compiled by $T_{33}$-stress in the general form of (5). In (5), the similar power law relationship between $J_{c}$ and $T_{33}$ was also valid for the combination of S55C [14, 15] and SCM440 [17] tested using both CT and $3 \mathrm{~PB}$ specimens. In addition, $T_{33}$, which seemed to be useful for predicting the bounded nature of $J_{c}$ for S55C [16], has also been proven to be valid for A533B. In these empirical equations, the TST effect and the bounded nature of $J_{c}$ were described with a single out-of-plane elastic parameter $T_{33}$ taken at the specimen midplane. Although the depicted relationship between the fracture toughness $J_{c}$ of a material and $T_{33}$ must be validated for other materials and other types of test specimen configurations, using $T_{33}$ as a relevant out-of-plane constraint parameter is definitely worthy of further investigation.

It could be argued that the relationship $J_{c} \propto B^{(-1 / 2)} \propto$ $\left|T_{33}\right|^{0.6}$ (Figure 3) is similar to the formulation deduced from the SWL model, but no more than what is predicted by the
SWL model $\left(J_{c} \propto B^{(-1 / 2)}\right)[2]$, because $\left|T_{33}\right|$ first approaches to 0 for large TST (Note: with increase in TST for 3PB specimen, negative $T_{33}$ first increases, crosses 0 and converges to $\left.v T_{11}\right)$. As Anderson et al. indicated, as a contradiction of the SWL model, the "fracture toughness does not decrease indefinitely with thickness [6]." On the point that $T_{33}$ exhibits a saturating tendency for large TST, $T_{33}$ has also been proven to be able to predict the bounded behavior of $J_{c}$ (Figure 3). The advantage of using $T_{33}$ is that $T_{33}$ has the characteristic to not only describe the TST effect on $J_{c}$ but to also predict the bounded nature of $J_{c}$. This advantage of $T_{33}$ successfully avoids the contradiction deduced from the SWL model; that is, $J_{c} \rightarrow 0$ for $B \rightarrow \infty$.

ASTM E1921 [19] presents a method to adjust $J_{c}$ for CT's TST change by considering the empirical relationship $J_{c} \propto$ $B^{(-1 / 2)}$, under the assumption that 1-inch (1T) thickness CT toughness data exists. The presented method in this paper for a $3 \mathrm{~PB}$ specimen can be generally applied to any type of test specimens, if a curve similar to Figure 2 is obtained. The fact that 1T CT test data are not necessary for our method can help practitioners in their works.

When the proposed general formulation of (3) is practically used for determining the lower bound of $J_{c}$ for a specific material tested with a fracture toughness test specimen, the material constants $C$ and $\gamma$ should be first determined by conducting measurements on at least two different-sized 


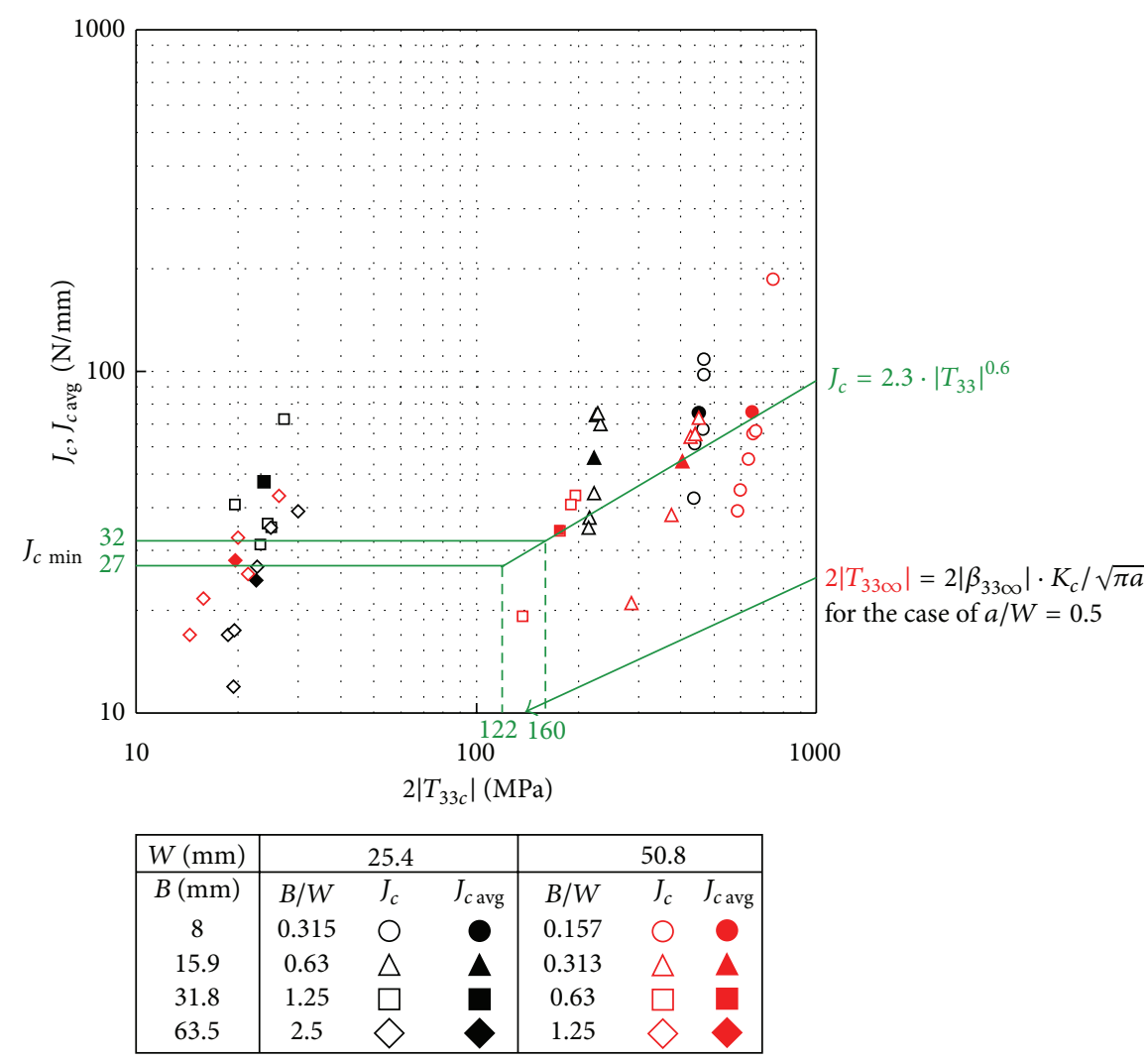

FIgURE 3: Relationship between $J_{c}$ and $T_{33 c}\left(\mathrm{~A} 533 \mathrm{~B},-91^{\circ} \mathrm{C}, 3 \mathrm{~PB}\right)$.

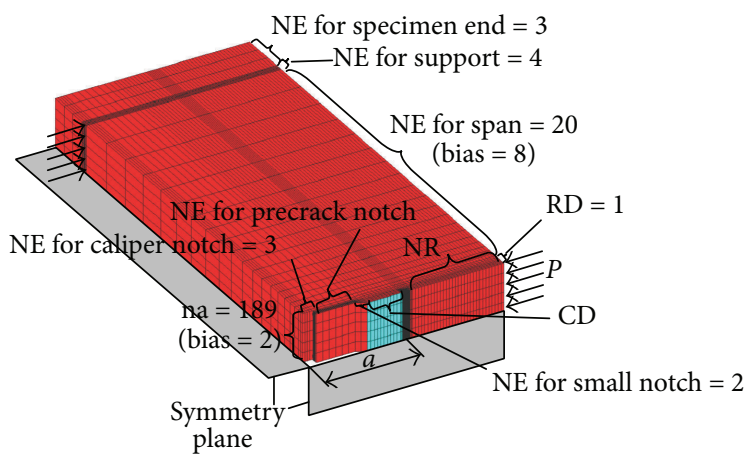

(a) Global mesh

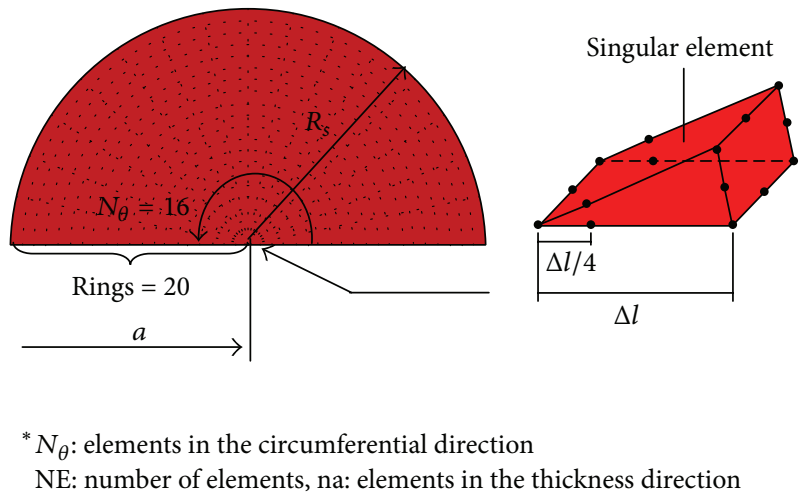

(b) Details of crack-tip for elastic analysis

FIgURE 4: Typical finite element model of the 3PB specimen.

specimens. Nevertheless, if measurements on only one size of specimen are conducted, (3) can also be simply but not accurately applied for predicting the lower bound fracture toughness just by assuming $\gamma=1 / 2$ in the relationship $J_{c} \propto\left|T_{33}\right|^{\gamma}$ for that one size of specimen considered, because the material constant $\gamma=1 / 2$ has been verified for the materials S55C and SCM440 tested with both CT and 3PB specimens $[14,15,17]$; in addition, this work validated that the approximated $\gamma=0.6$ which is close to $\gamma=1 / 2$ was applicable for the material A533B tested using $3 \mathrm{~PB}$ specimens.

The normalized $T_{33}$-stress solutions used in this work were taken at the specimen midplane. It is true that these values are distributed in the specimen thickness direction [21]. There are many possibilities to treat this $3 \mathrm{D}$ effect, but, considering the fact that the fracture tends to initiate at the specimen midplane, the values at the specimen midplane were chosen to represent the characteristic intensity of these values.

\section{Conclusions}

This paper demonstrated for the decommissioned Shoreham reactor vessel steel A533B [1] that the out-of-plane crack-tip constraint has a noticeable contribution to the TST effect 
TABLE 3: Summary of the generated mesh for elastic analysis $\left(S / W=4, R_{s}=0.4 \mathrm{~mm}\right)$.

\begin{tabular}{|c|c|c|c|c|c|c|c|c|}
\hline \multicolumn{2}{|c|}{$W \mathrm{~mm} B / W$} & \multirow{2}{*}{$\begin{array}{l}a / W \\
0.49 \\
0.50\end{array}$} & \multirow{2}{*}{$\begin{array}{c}\Delta l / a \\
0.0016\end{array}$} & Number of elements (NE) for precrack notch & \multirow[t]{2}{*}{ CD } & \multirow{2}{*}{$\begin{array}{c}\mathrm{NR} \\
30\end{array}$} & \multirow{2}{*}{$\begin{array}{l}\text { Nodes } \\
368609\end{array}$} & \multirow{2}{*}{$\begin{array}{c}\text { Elements } \\
87591\end{array}$} \\
\hline \multirow{4}{*}{25.4} & 0.315 & & & \multirow{4}{*}{6} & & & & \\
\hline & 0.63 & 0.52 & 0.0015 & & \multirow{3}{*}{10} & 28 & 366579 & 87143 \\
\hline & 1.25 & $\begin{array}{l}0.52 \\
0.53\end{array}$ & 0.0015 & & & 30 & 368609 & 87591 \\
\hline & 2.5 & $\begin{array}{l}0.49 \\
0.50 \\
\end{array}$ & 0.0016 & & & 30 & 368609 & 87591 \\
\hline \multirow{4}{*}{50.8} & 0.157 & $\begin{array}{l}0.48 \\
0.49\end{array}$ & $\begin{array}{l}0.00082 \\
0.00080\end{array}$ & \multirow{4}{*}{10} & $\begin{array}{c}9 \\
10\end{array}$ & $\begin{array}{l}30 \\
30\end{array}$ & $\begin{array}{l}371654 \\
372669\end{array}$ & $\begin{array}{l}88263 \\
88487\end{array}$ \\
\hline & 0.313 & 0.49 & 0.00080 & & 10 & 30 & 372669 & 88487 \\
\hline & 0.63 & 0.50 & 0.00079 & & 9 & 30 & 371654 & 88263 \\
\hline & 1.25 & $\begin{array}{l}0.51 \\
0.52 \\
\end{array}$ & $\begin{array}{l}0.00077 \\
0.00076\end{array}$ & & $\begin{array}{l}12 \\
15\end{array}$ & $\begin{array}{l}28 \\
25\end{array}$ & 372669 & 88487 \\
\hline
\end{tabular}

TABLE 4: Normalized $T_{33}$-stress solutions $\left(\beta_{33}\right)$ at the specimen midplane for $3 \mathrm{~PB}$ specimens $(\nu=0.29)$.

\begin{tabular}{lccccc}
\hline \multicolumn{3}{c}{$W=25.4 \mathrm{~mm}$} & \multicolumn{3}{c}{$W=50.8 \mathrm{~mm}$} \\
$B / W$ & $a / W$ & $\beta_{33}$ & $B / W$ & $a / W$ & $\beta_{33}$ \\
\hline \multirow{2}{*}{0.315} & 0.49 & -0.582 & \multirow{2}{*}{0.157} & 0.48 & -0.938 \\
& 0.50 & -0.583 & & 0.49 & -0.947 \\
\hline 0.63 & 0.52 & -0.281 & 0.313 & 0.49 & -0.596 \\
\hline \multirow{2}{*}{1.25} & 0.52 & -0.032 & \multirow{2}{*}{0.63} & 0.50 & -0.298 \\
& 0.53 & -0.025 & & & \\
\hline \multirow{2}{*}{2.5} & 0.49 & 0.031 & \multirow{2}{*}{1.25} & 0.51 & -0.041 \\
& 0.50 & 0.037 & & 0.52 & -0.034 \\
\hline
\end{tabular}

on $J_{c}$ and that the magnitude of this out-of-plane cracktip constraint can be described by the elastic $T_{33}$-stress. The experimental expression of the TST effect on $J_{c}$ using $T_{33^{-}}$ stress, which was proposed for $0.55 \%$ carbon steel S55C and $0.40 \%$ carbon chromium molybdenum steel SCM440 with both CT and 3PB specimens in our previous work $[14,15,17]$, was shown to be a correct description for A533B. In concrete, the experimental relationship for A533B was compiled as $J_{c}[\mathrm{~N} / \mathrm{mm}]=2.3 \cdot\left|T_{33}\right|^{0.6}\left(80 \leq\left|T_{33}\right| \leq 320 \mathrm{MPa}\right)$ to describe the $J_{c}$ decreasing tendency for increasing TST. Because the Shoreham data included a lower bound $J_{c}$ for increasing TST, a new discovery was that $T_{33}$ successfully predicted the lower bound of $J_{c}$ with increasing TST. This lower bound of $J_{c}$ prediction with $T_{33}$ resolved the contradiction that the empirical $J_{c} \propto(\mathrm{TST})^{-1 / 2}$ predicts $J_{c}=0$ for large TST.

\section{Appendix}

The normalized $\beta_{33}$ solutions used to calculate $T_{33 c}$ in Tables 1 and 2 were obtained from the elastic FEA. In the present $\mathrm{FEA}$, all the $3 \mathrm{~PB}$ specimen dimensions were specified in accordance with those recorded in [1], and the material properties were set to be consistent with those specified in [20] for A533B.
The typical FEA model of the 3PB specimen used in the present elastic analysis is shown in Figure 4, with the details for the generated mesh being summarized in Table 3 . The details of the elastic FEA procedure can be found in our recent work [17]. The normalized $T_{33}$-stress, $\beta_{33}$, at the specimen midplane is summarized in Table 4 , which is in a good agreement with the interpolated solutions from our previous results [22].

\section{Nomenclature}

$B:$

C: $\quad$ Material constant (see (3))

E: $\quad$ Young's modulus

$J: \quad J$-integral

$J_{c}$ and $J_{c \text { avg }}$ : Fracture toughness and its average

$J_{c \text { min }}: \quad$ Lower bound fracture toughness

$K_{\mathrm{I}}: \quad \quad$ Local mode I stress intensity factor (SIF)

$K_{I c}: \quad$ Fracture toughness $\left(K_{I c}=\left[E \cdot J_{c} /\left(1-v^{2}\right)\right]^{1 / 2}\right)$

$K_{c}: \quad$ SIF corresponding to fracture load

$P_{c}: \quad$ Fracture load

$R_{S}: \quad$ Crack tube radius

$S: \quad$ Support span for 3PB specimen

$T_{11}$ and $T_{33}: T$-stresses

$T_{33 c}: \quad T_{33}$-stress corresponding to fracture load

$T_{330}$ : $\quad$ Bounded value of $T_{33}$-stress

$W: \quad$ Specimen width

$a: \quad$ Crack length

$r, \theta: \quad$ In-plane polar coordinates

$x_{j}$ : $\quad$ Crack-tip local coordinates $(j=1,2,3)$

$\Delta l: \quad$ Singular element size

$\Sigma: \quad$ Standard deviation

$\beta_{11}, \beta_{33}: \quad$ Normalized forms of the $T$-stresses

$\beta_{3300}$ : $\quad$ Bounded value of $\beta_{33}$

$\gamma: \quad$ Material constant (see (3))

$\mu$ : $\quad$ Average value

$v: \quad$ Poisson's ratio

$\sigma_{i j}: \quad$ Stress components $(i, j=1,2,3)$. 


\section{Conflict of Interests}

The authors declare that there is no conflict of interests regarding the publication of this paper.

\section{Acknowledgments}

This work was supported in part by JSPS KAKENHI Grant no. 24561038 . Their support is greatly appreciated.

\section{References}

[1] H. J. Rathbun, G. R. Odette, T. Yamamoto, and G. E. Lucas, "Influence of statistical and constraint loss size effects on cleavage fracture toughness in the transition-a single variable experiment and database," Engineering Fracture Mechanics, vol. 73, no. 1, pp. 134-158, 2006.

[2] K. Wallin, "The size effect in $K_{\text {IC }}$ results," Engineering Fracture Mechanics, vol. 22, no. 1, pp. 149-163, 1985.

[3] M. Nevalainen and R. H. Dodds Jr., "Numerical investigation of 3-D constraint effects on britttle fracture in $\mathrm{SE}(\mathrm{B})$ and $\mathrm{C}(\mathrm{T})$ specimens," International Journal of Fracture, vol. 74, no. 2, pp. 131-161, 1995.

[4] R. H. Dodds Jr., T. L. Anderson, and M. T. Kirk, "A framework to correlate $\mathrm{a} / \mathrm{W}$ ratio effects on elastic-plastic fracture toughness $\left(J_{c}\right)$," International Journal of Fracture, vol. 48, no. 1, pp. 1-22, 1991.

[5] M. T. Kirk, R. H. Dodds, and T. L. Anderson, "An approximate technique for predicting size effects on cleavage fracture toughness $\left(J_{c}\right)$ using the elastic T stress," in Fracture Mechanics, J. D. Landes, D. E. Mccabe, and J. A. M. Boulet, Eds., vol. 24, pp. 6286, American Society for Testing and Materials, Philadelphia, $\mathrm{Pa}$, USA, 1994.

[6] T. L. Anderson, D. Stienstra, and R. H. Dodds, "A theoretical framework for addressing fracture in the ductile-brittle transition region," in Fracture Mechanics, J. D. Landes, D. E. Mccabe, and J. A. M. Boulet, Eds., vol. 24, pp. 186-214, American Society for Testing and Materials, Philadelphia, Pa, USA, 1994.

[7] T. J. Theiss and J. W. Bryson, "Influence of crack depth on the fracture toughness of reactor pressure vessel steel," in Constraint Effects in Fracture, E. M. Hackett, Ed., pp. 104-119, American Society for Testing and Materials, Philadelphia, Pa, USA, 1993.

[8] J. D. G. Sumpter, "An experimental investigation of the $T$ stress approach," in Constraint Effects in Fracture, E. M. Hackett, Ed., pp. 495-502, American Society For Testing and Materials, Philadelphia, Pa, USA, 1993.

[9] M. T. Kirk, K. C. Koppenhoefer, and C. F. Shih, "Effect of constraint on specimen dimensions needed to obtain structurally relevant toughness measures," in Constraint Effects in Fracture, E. M. Hackett, Ed., pp. 79-103, American Society for Testing and Materials, Philadelphia, Pa, USA, 1993.

[10] J. P. Petti and R. H. Dodds Jr., "Coupling of the Weibull stress model and macroscale models to predict cleavage fracture," Engineering Fracture Mechanics, vol. 71, no. 13-14, pp. 20792103, 2004.

[11] K. Wallin, T. Saario, and K. Torronen, "Statistical model for carbide induced brittle fracture in steel," Metal Science, vol. 18, no. 1, pp. 13-16, 1984.

[12] T. Lin, A. G. Evans, and R. O. Ritchie, "A statistical model of brittle fracture by transgranular cleavage," Journal of the Mechanics and Physics of Solids, vol. 34, no. 5, pp. 477-497, 1986.
[13] C. Ruggieri, "Probabilistic treatment of fracture using two failure models," Probabilistic Engineering Mechanics, vol. 13, no. 4, pp. 309-319, 1998.

[14] T. Meshii and T. Tanaka, "Experimental $T_{33}$-stress formulation of test specimen thickness effect on fracture toughness in the transition temperature region," Engineering Fracture Mechanics, vol. 77, no. 5, pp. 867-877, 2010.

[15] T. Tanaka and T. Meshii, "Formulating test specimen thickness effect on fracture toughness with $T_{33}$-stress: case of 3PB test specimen," in Proceedings of the ASME Pressure Vessels and Piping Division/K-PVP Conference (PVP '10), pp. 1213-1219, Seattle, Wash, USA, July 2010.

[16] T. Meshii, K. Lu, and R. Takamura, "A failure criterion to explain the test specimen thickness effect on fracture toughness in the transition temperature region," Engineering Fracture Mechanics, vol. 104, pp. 184-197, 2013.

[17] T. Meshii and T. Tanaka, "Framework to correlate test specimen thickness effect on fracture toughness with $T_{33}$-stress," in Proceedings of the ASME Pressure Vessels and Piping Conference, pp. 1109-1117, Baltimore, Md, USA,Baltimore, Md, USA, 2011.

[18] T. Nakamura and D. M. Parks, "Determination of elastic Tstress along three-dimensional crack fronts using an interaction integral," International Journal of Solids and Structures, vol. 29, no. 13, pp. 1597-1611, 1992.

[19] ASTM, E1921-10 Standard test method for determination of reference temperature, $T_{0}$, for ferritic steels in the transition range. Annual Book of ASTM Standards. American Society for Testing and Materials, Philadelphia, Pa, USA, 2010.

[20] H. J. Rathbun, G. R. Odette, M. Y. He, and T. Yamamoto, "Influence of statistical and constraint loss size effects on cleavage fracture toughness in the transition-a model based analysis," Engineering Fracture Mechanics, vol. 73, no. 18, pp. 2723-2747, 2006.

[21] J. Qu and X. Wang, "Solutions of T-stresses for quarter-elliptical corner cracks in finite thickness plates subject to tension and bending," International Journal of Pressure Vessels and Piping, vol. 83, no. 8, pp. 593-606, 2006.

[22] K. Lu and T. Meshii, "Three-dimensional T-stresses for threepoint-bend specimens with large thickness variation," Engineering Fracture Mechanics, pp. 197-203, 2014. 

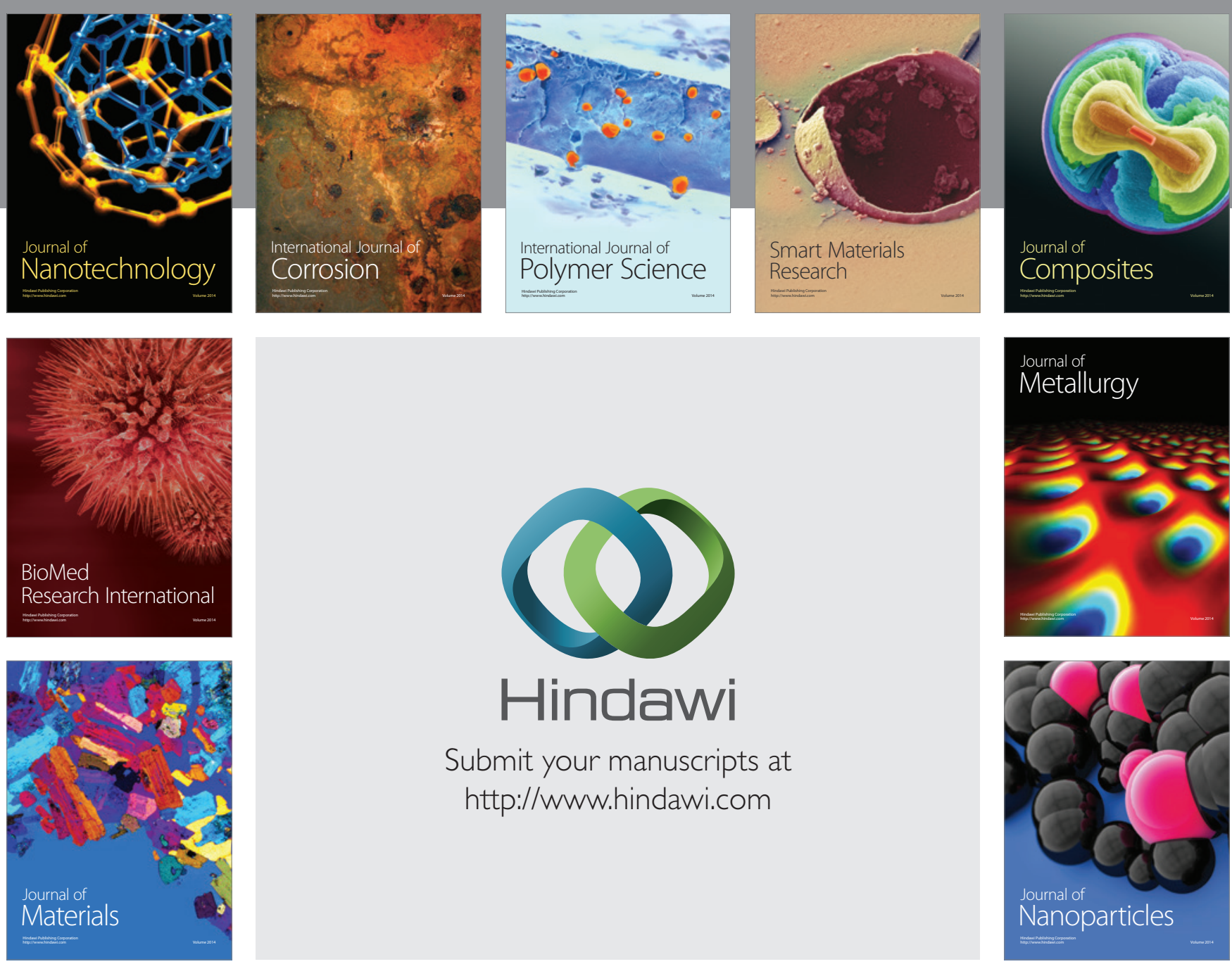

Submit your manuscripts at http://www.hindawi.com
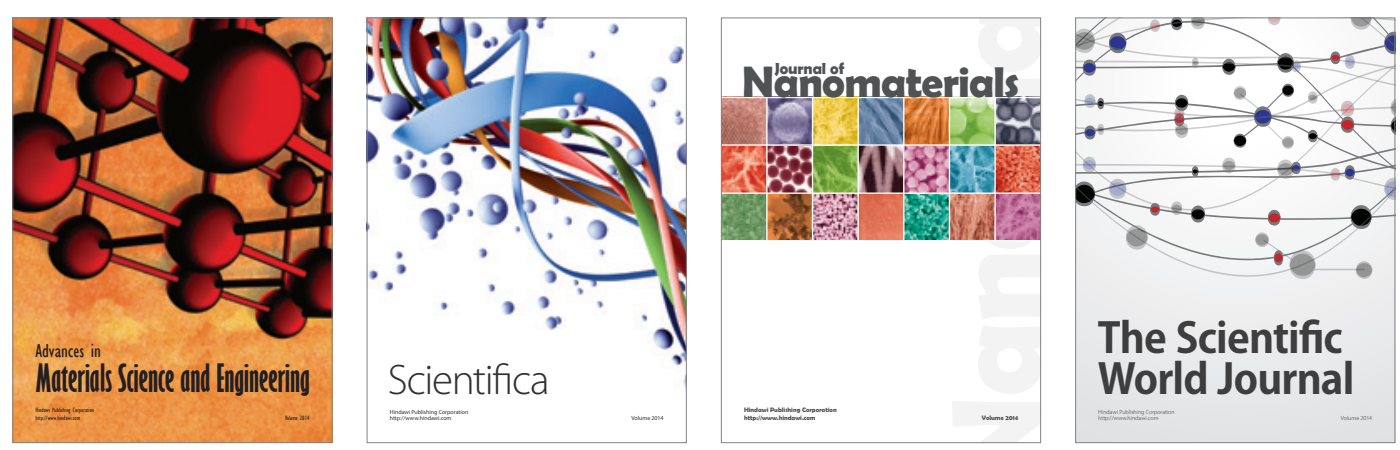

\section{The Scientific World Journal}
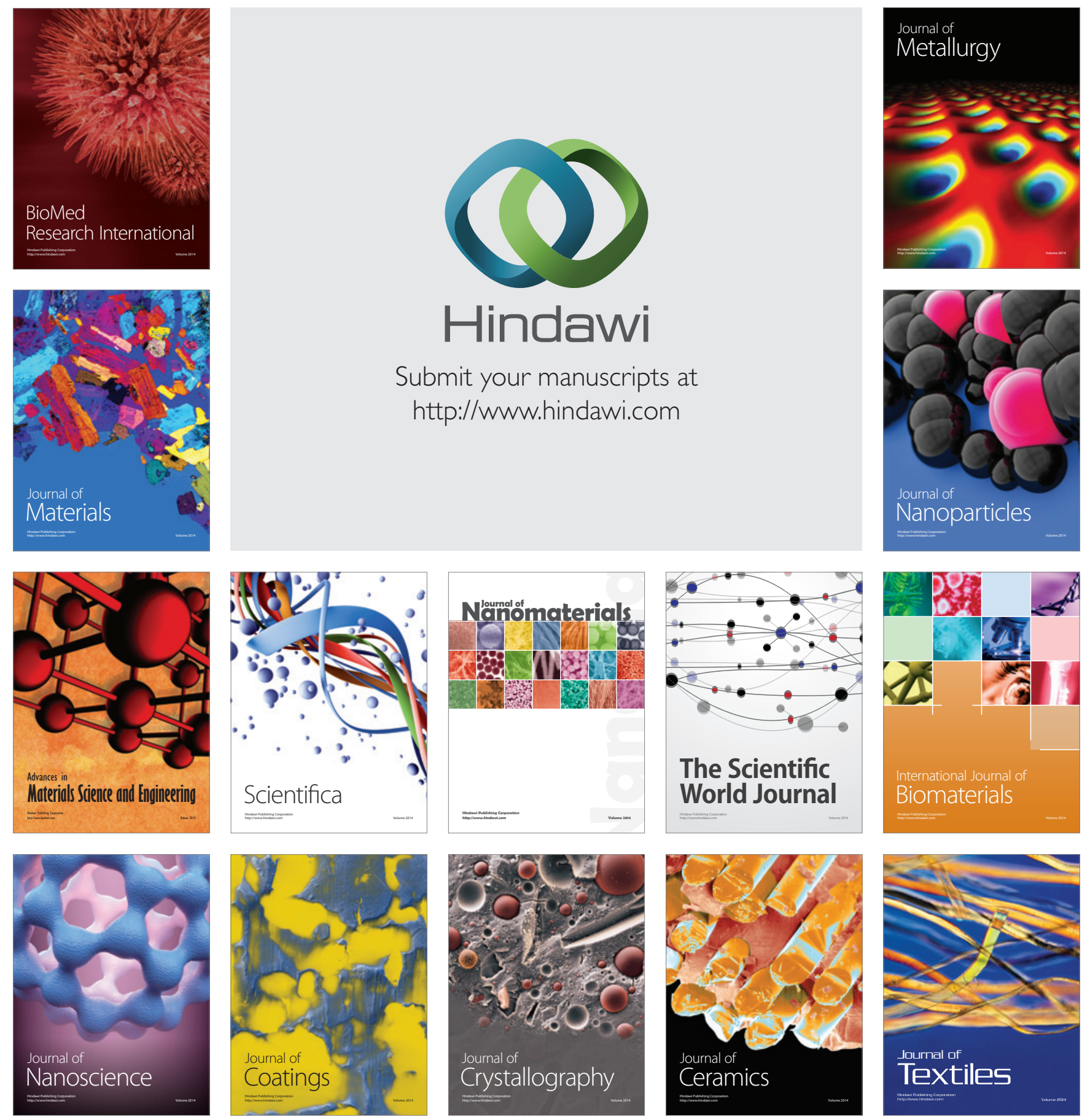